\title{
Using Conditional Value at Risk (CVaR) to select radiata pine trees for operational deployment
}

\author{
Uso del valor en riesgo condicional (CVaR) para seleccionar árboles \\ de Pinus radiata para establecimiento operacional
}

\author{
Antonio A Pinto ${ }^{a *}$, Rosa M Alzamora ${ }^{b}$, Luis A Apiolaza ${ }^{c}$ \\ *Corresponding author: ${ }^{a}$ Universidad de Concepción, Facultad de Agronomía, Barrio Universitario, \\ Casilla 160-C, Concepción, Chile, tel.: 56-41-2661439, anpinto@udec.cl \\ b Universidad de Concepción, Departamento de Manejo de Bosques y Medio Ambiente, \\ Victoria 631, Concepción, Chile, tel.: 56- 41-2204905, ralzamora@udec.cl \\ c University of Canterbury, School of Forestry, Private Bag 4800, Christchurch, New Zealand, \\ tel.:64-3-364 2126, Luis.Apiolaza@canterbury.ac.nz
}

\begin{abstract}
SUMMARY
Conditional Value at Risk (CVaR) was used to account for risk when building a portfolio of Pinus radiata trees for operational plantation deployment, under hypothetical changes on volume, modulus of elasticity, resin defects and lumber prices. The study considers three groups of trees grown to produce appearance lumber, structural lumber, or both. The CVaR model selected structural trees, which had high and variable returns across a wide range of risks, especially under low aversion scenarios; however, as risk-aversion increased, the model diversified incorporating trees producing both structural and appearance grades. Similarly, trees producing solely appearance grades, characterized by having the lowest returns variability, were only incorporated in scenarios of high risk-aversion.
\end{abstract}

Key words: radiata pine, wood traits, portfolio selection, CVaR.

\section{RESUMEN}

El valor en riesgo condicional (CVaR) se utilizó para representar el riesgo al desarrollar un portafolio de árboles de Pinus radiata, para ser utilizado en plantaciones operacionales, bajo hipotéticos cambios en volumen, módulo de elasticidad, defectos por resina y precios de madera. El estudio consideró tres grupos de árboles formados para producir madera de apariencia, madera estructural, o ambas. El modelo CVaR seleccionó árboles estructurales, los cuales tuvieron rendimientos altos y variables en un amplio rango de riesgo, pero especialmente en escenarios de baja aversión al riesgo; sin embargo, a medida que la aversión al riesgo incrementó, el modelo diversificó e incorporó árboles que producían, conjuntamente, madera estructural y de apariencia. Similarmente, los árboles que produjeron solo madera de apariencia, caracterizados por tener la variabilidad más baja en los retornos, fueron solo incorporados en escenarios de alta aversión al riesgo.

Palabras clave: Pinus radiata, atributos de madera, selección de portafolios, CVaR.

\section{INTRODUCTION}

Forest firms have a choice of genetic material when establishing plantations, with different deployment units (families or clones) containing varying combinations of traits (e.g. volume, wood properties, etc.). In addition, there is uncertainty about future product prices and environmental conditions during a rotation. Therefore firms face the problem of choosing genetic material that maximizes log recovery value while maintaining enough variability to keep risk at an acceptable level.

There are a few key wood traits that explain most of the log recovery value; see Apiolaza and Alzamora (2013) for a full description. Volume is the most important trait for appearance lumber, although resin defects also affect the recovery value of clear grades. For structural grades, volume and modulus of elasticity (MoE) are the most relevant traits; in turn MoE also affects dimensional stability and therefore appearance lumber. In addition, silvicultural decisions affect volume and wood properties via stocking. Variability for these traits generates risk for recovery value.

Apiolaza and Alzamora (2013) pointed out that tree selection for deployment could be seen as an investment decision when considering expected profits and variability. They proposed using portfolio theory relying on the mean absolute deviation, MAD (Konno and Yamazaki 1991), for the analysis of return-risk tradeoffs for trees as a result of 
wood traits variability to build 'deployment portfolios'. However, the objective of this model was to reduce the mean absolute deviation of tree returns, without a particular consideration on losses.

Several alternative models have been proposed to deal with risk since Markowitz's (1952) portfolio selection theory. Downside risk models, such as Conditional Value at Risk (CVaR), have been used in different problems where extreme losses can occur. CVaR represents the conditional expected losses exceeding a selected percentile $\alpha$ of the loss distribution (Artzner et al. 1999, Rockafellar and Uryasev 2002).

Comparing CVaR and MAD models, Angelelli et al. (2008) noticed that CVaR appeared to generate more stable portfolios, especially under unstable markets. One drawback is that $\mathrm{CVaR}$ is much more computationally intensive while MAD optimization can be solved in few seconds. Topaloglou et al. (2002) also compared CVaR and MAD in a study that analyzed multicurrency asset allocation problems. Both models had similar portfolio selection; nevertheless, when they were evaluated in back-testing experiments with real market data, the CVaR model had a better performance, which was more evident with low-risk portfolios.

This note extends Apiolaza and Alzamora's (2013) work by using CVaR to evaluate changes in decisions to produce appearance lumber, structural lumber, or both, considering tradeoffs between return and variability. Variability is represented as scenarios of volume, MoE, resin defects and lumber prices derived from a range of representative conditions of site and silviculture for Chile and New Zealand. The discussion focuses on the comparison of $\mathrm{CVaR}$ and MAD when building deployment portfolios. We hypothesize that CVaR would be an efficient tool for selecting trees under variability, when the objective is to reduce losses in their expected recovery value.

\section{METHODS}

Data consisted of three groups of 34 trees grown to produce appearance lumber, structural lumber, or both, in total 102 trees presented by Apiolaza and Alzamora (2013). Appearance grades correspond to products described by WWPA (1995); whereas the structural study considered New Zealand grades 6, 8, 10 and 12, where the number represents MoE in GPa. The first group of appearance trees prioritized the production of appearance grades from the first pruned log, and second and third unpruned logs. The second group of structural trees was processed to mainly produce structural grades from the first, second and third unpruned logs. Finally, a third group of appearance-structural trees produced appearance grades from the first pruned log, and structural lumber from two upper unpruned logs. For more detail, see Apiolaza and Alzamora (2013).

Revenue per tree was calculated as the sum of log recovery values for the first, second and third logs; whereas upper sawlogs and pulplogs were valued at market pri- ce. Log recovery value corresponded to the total value of lumber in one cubic meter of logs less the processing cost (see Table 1). The economic return per tree was estimated as the net annual equivalent value ( $\mathrm{NZ} \$$ stem $^{-1}$ year $^{-1}$ ), from a cash flow including costs of establishment, silviculture, harvesting and the tree revenue with a discount rate of $10 \%$ (table 2).

Scenarios for wood traits and variability of prices. There were seven main variability scenarios: the base scenario with current data, three positive and three negative scenarios generated by changing tree volume, $\mathrm{MoE}$, and resin defects:

- Two scenarios either increase or reduce small end diameter (SED) of the logs by $10 \%$.

- Two scenarios either increase or reduce MoE by $10 \%$. We assumed that MoE had no effect on the value of appearance grades and that resin did not affect the value of structural lumber. Resin problems were modeled applying damage relationships between bleeding and outturn based on a Chilean resin study (Meneses and Guzmán 2003).

- Two scenarios changed a combination of traits. An optimistic scenario increased SED by $25 \%$ and MoE by $25 \%$ for all logs. A pessimistic scenario decreased SED by $25 \%$ and MoE by $25 \%$, as well as introduced resin problems.

These seven scenarios were run under three product price scenarios: 1) current prices; 2) prices increased by $20 \%$; and, 3) prices reduced by $20 \%$.

Additionally, we generated more variability by assuming that a randomly selected $30 \%$ of the trees stayed in the base scenario while the rest of the trees shifted to a different one. This shifting was randomized 1,000 times per group of trees. Thus, there were 1021 scenarios per trees and the equivalent of 104,142 trees (see table 2).

Table 1.Prices and shipping costs for products and processing costs for logs.

Precios, costos de transporte, y costos de procesamiento de trozos.

\begin{tabular}{|c|c|c|c|}
\hline Item & $\begin{array}{l}\text { Price/cost } \\
{\left[\mathrm{NZ} \$ / \mathrm{m}^{3}\right]}\end{array}$ & Item & $\begin{array}{l}\text { Price/cost } \\
{\left[\mathrm{NZ} \$ / \mathrm{m}^{3}\right]}\end{array}$ \\
\hline$M \& B^{(a)}$ & 815 & MSG8 $^{(s)}$ & 640 \\
\hline 3rd $\mathrm{Clr}^{(\mathrm{a})}$ & 550 & MSG6 (s) & 500 \\
\hline Shop $1^{\text {(a) }}$ & 520 & Reject & 230 \\
\hline Shop $2^{\text {(a) }}$ & 458 & FJ Blocks & 512 \\
\hline Shop $3^{\text {(a) }}$ & 372 & FJ Out & 359 \\
\hline MSG12 (s) & 800 & Shipping cost & 85 \\
\hline MSG10 (s) & 720 & Processing cost & 180 \\
\hline
\end{tabular}

(a) Appearance grade and (s) structural grades 
Table 2. Descriptive statistics (in NZ\$ stem ${ }^{-1}$ year $^{-1}$ ) of tree returns, according to traits and prices scenarios.

Descriptores estadísticos (NZ\$ árbol ${ }^{-1} \mathrm{año}^{-1}$ ) de los retornos por árbol, de acuerdo a los escenarios de características y precios.

\begin{tabular}{|c|c|c|c|c|c|c|c|}
\hline Parameter & $\begin{array}{c}\text { Base } \\
\text { scenario }\end{array}$ & $\begin{array}{l}\text { Volume } \\
\text { increase }\end{array}$ & $\begin{array}{l}\text { Volume } \\
\text { decrease }\end{array}$ & $\begin{array}{c}\text { MoE } \\
\text { increase }\end{array}$ & $\begin{array}{c}\text { MoE } \\
\text { decrease }\end{array}$ & Pessimistic & Optimistic \\
\hline \multicolumn{8}{|c|}{ Current product prices } \\
\hline \multicolumn{8}{|c|}{ Appearance trees } \\
\hline Mean & 0.59 & 1.02 & 0.66 & 0.59 & 0.59 & -0.62 & 1.59 \\
\hline Standard deviation & 0.52 & 0.69 & 0.47 & 0.52 & 0.52 & 0.47 & 0.92 \\
\hline \multicolumn{8}{|c|}{ Appearance-structural trees } \\
\hline Mean & 1.23 & 1.66 & 1.03 & 2.26 & 0.92 & -0.46 & 4.62 \\
\hline Standard deviation & 0.68 & 0.81 & 0.55 & 0.85 & 0.55 & 0.16 & 1.60 \\
\hline \multicolumn{8}{|c|}{ Structural trees } \\
\hline Mean & 0.76 & 1.06 & 0.71 & 1.75 & 0.26 & -0.44 & 4.77 \\
\hline Standard deviation & 0.92 & 1.15 & 0.76 & 0.96 & 0.73 & 0.27 & 1.86 \\
\hline \multicolumn{8}{|c|}{ Product prices increased by $20 \%$} \\
\hline \multicolumn{8}{|c|}{ Appearance trees } \\
\hline Mean & 1.22 & 1.86 & 1.23 & 1.22 & 1.22 & -0.35 & 2.69 \\
\hline Standard deviation & 0.65 & 0.88 & 0.60 & 0.65 & 0.65 & 0.44 & 1.18 \\
\hline \multicolumn{8}{|c|}{ Appearance-structural trees } \\
\hline Mean & 2.42 & 3.10 & 1.99 & 4.10 & 1.85 & -0.30 & 8.05 \\
\hline Standard deviation & 1.21 & 1.44 & 0.95 & 1.35 & 0.87 & 0.19 & 2.69 \\
\hline \multicolumn{8}{|c|}{ Structural trees } \\
\hline Mean & 1.77 & 2.32 & 1.55 & 3.53 & 0.93 & -0.38 & 8.75 \\
\hline Standard deviation & 1.68 & 2.07 & 1.37 & 1.72 & 1.20 & 0.30 & 3.36 \\
\hline \multicolumn{8}{|c|}{ Product prices reduced by $20 \%$} \\
\hline \multicolumn{8}{|c|}{ Appearance trees } \\
\hline Mean & -0.13 & 0.07 & 0.02 & -0.13 & -0.13 & -0.93 & 0.33 \\
\hline Standard deviation & 0.48 & 0.61 & 0.42 & 0.48 & 0.48 & 0.51 & 0.79 \\
\hline \multicolumn{8}{|c|}{ Appearance-structural trees } \\
\hline Mean & -0.08 & 0.07 & -0.02 & 0.64 & -0.26 & -0.83 & 1.84 \\
\hline Standard deviation & 0.38 & 0.44 & 0.29 & 0.72 & 0.33 & 0.15 & 1.02 \\
\hline \multicolumn{8}{|c|}{ Structural trees } \\
\hline Mean & -0.62 & -0.61 & -0.41 & 0.01 & -0.90 & -0.71 & 1.27 \\
\hline Standard deviation & 0.65 & 0.79 & 0.50 & 0.68 & 0.57 & 0.25 & 1.30 \\
\hline
\end{tabular}

Portfolio model. The objective function minimizes the conditional value at risk $(\alpha-\mathrm{CVaR})$ of the losses regarding a target tree return, for a confident level $\alpha$. The mathematical formulation is:

Minimize $\mathrm{CVaR}_{\alpha}: \eta+\frac{\sum_{\mathrm{s}=1}^{\mathrm{s}} \phi^{\mathrm{s}} \mathrm{v}}{1-\alpha}$
Subject to

$$
\begin{gathered}
\sum_{i=1}^{N} x_{i}=1 \\
\sum_{i=1}^{N} \sum_{s=1}^{S} \phi^{s} R_{i, s} x_{i} \geq T \\
\mathrm{I}_{s}=Y-\sum_{i=1}^{N} R_{i, s} x_{i} \quad \forall s
\end{gathered}
$$




$$
\begin{gathered}
\mathrm{v}_{\mathrm{s}} \geq \mathrm{I}_{\mathrm{s}}-\eta \quad \forall s \\
\mathrm{x}_{\mathrm{i}} \geq 0, \mathrm{v}_{\mathrm{s}} \geq 0, \eta \text { (free), } \mathrm{I}_{\mathrm{s}} \text { (free) }
\end{gathered}
$$

Equation [1] is the objective function and it represents the $\alpha-\mathrm{CVaR}$, which is the conditional expectation of the losses above $\eta(\alpha-\mathrm{CVaR})$ at confidence level of $\alpha$. The auxiliary variable $\mathrm{V}_{\mathrm{s}}$ accounts for the losses above $\eta$, and $\phi^{\mathrm{s}}$ is the probability of occurrence of scenario $s=1, \ldots, 1021$. Constrains of the model are represented by equations [2] to [6]. Equation [2] forces the sum of the proportion of the portfolio invested in the chosen trees $X_{i}$ to equal one, where $i$ is the tree and $i=1, \ldots, 102$. In other words, this constrain indicates that the whole budget must be used in selecting trees. Equation [3] indicates that the mean return of the selected portfolio across the scenarios $\left(\phi^{5} R_{1,5} X_{1}\right)$ should be higher than a minimum expected return equal to $T$, which is a return threshold imposed by the decision maker. Equation [4] shows the function of losses; thus, $I_{s}$ represents the losses, in each scenario $s$, given a minimum return threshold of Y. Accordingly, if the portfolio return in a particular scenario is lower than $Y$, the $I_{s}$ function will account for a loss equal to $Y-\sum_{i}^{n} R_{i, s} X_{i}$. For this study, we are considering a T of NZ\$2.5, and a Y value of NZ\$2, which are based on the trends on tree returns across scenarios. Equation [5] shows the estimation of the auxiliary variable $\mathrm{V}_{\mathrm{s}}$ which is accounting for those losses above the value at risk $(\alpha-C V a R)$. Finally, constrains in Equation [6] specify the non-negativity conditions of decision variables.

\section{RESULTS}

In the base scenario, appearance trees (tree 1 to 34), had the lowest mean net return with NZ\$ 0.59 , whereas appearance-structural trees (tree 35 to 68 ) had the highest with NZ\$1.23. Although structural trees (tree 69 to 102) had high returns with NZ\$ 0.76, they displayed the highest variability as reflected in the standard deviation (see table 2). These trends remained across all scenarios; however, returns from structural trees were slightly superior to those from appearance-structural trees in the optimistic scenario. Due to increments in volume and MoE, every log of the structural trees increased its value while for the appearance-structural trees only the first log increased its value due to extra volume.

Selected trees varied according to the confidence value $\alpha$ of the loss distribution (table 3 ). When $\alpha$ ranged between 0.01 and 0.05 , the model selected only a structural tree (tree 86). As $\alpha$ increased from 0.06 to 0.99 the model diversified into more structural and appearance-structural trees such as trees 89, 48, 55, 61 and 65 . However, there were no appearance trees in the solution up to $\alpha$ of 0.66 , and from this point upwards the model apportioned the investment in the three types of trees. Finally, in selecting trees under a high risk-aversion scenario, $\alpha=0.09$, the portfolio included 31 trees: $13 \%$ were appearance trees, $42 \%$ appearancestructural trees and $45 \%$ structural trees. In addition, since the CVaR model limited the selection of trees in terms of expected returns $(T)$ and maximum losses per scenarios $(Y)$, the solution included not only trees with high variability, but also with high return.

Table 3. Changes in tree portfolio selection (\%) under different values of alpha $(\alpha)$.

\begin{tabular}{|c|c|c|c|c|c|c|c|c|c|c|c|c|c|c|c|c|}
\hline \multirow[t]{2}{*}{ Alpha $(\alpha)$} & \multicolumn{3}{|c|}{$\begin{array}{c}\text { Appearance trees } \\
(\%)\end{array}$} & \multicolumn{8}{|c|}{$\begin{array}{c}\text { Appearance-Structural trees } \\
(\%)\end{array}$} & \multicolumn{5}{|c|}{$\begin{array}{c}\text { Structural trees } \\
(\%)\end{array}$} \\
\hline & 30 & 31 & 37 & 48 & 50 & 52 & 55 & 56 & 57 & 61 & 65 & 71 & 82 & 84 & 86 & 89 \\
\hline 0.01 & - & - & - & - & - & - & - & - & - & - & - & - & - & - & 100 & - \\
\hline 0.05 & - & - & - & - & - & - & - & - & - & - & - & - & - & - & 100 & - \\
\hline 0.06 & - & - & - & - & - & - & 15 & - & - & - & - & - & - & - & 85 & - \\
\hline 0.10 & - & - & - & - & - & - & 21 & - & - & 15 & 13 & - & - & - & 47 & 5 \\
\hline 0.20 & - & - & - & 5 & - & - & 20 & 1 & - & 14 & 16 & - & - & - & 34 & 8 \\
\hline 0.30 & - & - & - & 8 & 2 & 1 & 17 & 7 & - & 13 & 15 & - & - & - & 25 & 6 \\
\hline 0.35 & - & - & - & 8 & 3 & 2 & 15 & 9 & 1 & 12 & 14 & - & 1 & 2 & 22 & 6 \\
\hline 0.66 & - & 2 & - & 8 & 7 & 5 & 12 & 10 & 5 & 10 & 10 & - & 3 & 3 & 15 & 4 \\
\hline 0.75 & - & 8 & - & 7 & 6 & 4 & 10 & 9 & 5 & 8 & 9 & 1 & 2 & 3 & 12 & 5 \\
\hline 0.90 & - & 8 & 3 & 6 & 5 & 3 & 10 & 7 & 3 & 7 & 8 & 2 & 4 & 2 & 10 & 3 \\
\hline 0.95 & - & 11 & 3 & 8 & 8 & 3 & 9 & 7 & 2 & 6 & 7 & 3 & 1 & 2 & 9 & 5 \\
\hline 0.99 & 11 & 21 & 1 & - & 7 & - & 20 & 10 & - & 5 & 8 & - & - & - & 13 & 3 \\
\hline
\end{tabular}

Cambios en la selección de árboles para el portafolio cuando varía el valor de alfa $(\alpha)$. 
Focusing on table 3 , tree 31 presented a high pruned log index (PLI) and a mean internode length (MIL) higher than $60 \mathrm{~cm}$; PLI and MIL are standard measures to assess the quality of pruned and unpruned logs, respectively (Park 1989, Watt et al. 2000). Tree 48 showed a high quality butt log, represented by its SED and PLI; however, its unpruned logs had lower MoE than those derived from structural tree 86. Tree 86 presented the highest MoE, indicating its intrinsic high quality to generate structural grades.

\section{DISCUSSION}

CVaR satisfied the goal of selecting good trees while avoiding extreme losses, and included trees that may have the highest profits. This portfolio of trees selected with $\mathrm{CVaR}$ was comparable to the one obtained by Apiolaza and Alzamora (2013) using MAD; however, the latter study did not consider scenarios of changing lumber prices. Under high levels of risk both models focused on structural trees, which had the highest expected returns and variability. This suggests that using genetically improved material (such as clones) for MoE could be a good option to reduce the risk of variable returns. When risk was reduced, i.e. lower MAD or better $\alpha$ in $\mathrm{CVaR}$, the composition of portfolios diversified toward appearancestructural trees. Producing appearance and structural grades from one tree had a hedging effect on returns, as there are phenotypic tradeoffs between MoE and volume under optimistic and pessimistic growing scenarios. In both, appearance-structural and structural trees, the structural logs had the highest value per tree, based mostly on the first pruned $\log$ and its traits. Both risk models diversified under conservative conditions, but with different proportions into the three groups: CVaR allocated a superior proportion of structural trees while MAD preferred appearance trees. Finally, either risk measure could be used to build deployment portfolios for operational plantations, particularly in well characterized genotypes (e.g. clonal populations).

\section{CONCLUSIONS}

The CVaR approach was suitable for selecting trees for deployment; although this was an experimental application, the selection showed robustness in terms of wood quality and returns. The high returns and variability displayed by structural trees suggest an opportunity for narrowing genetic variability, via clonal forestry, to make the returns from radiata pine structural grades lumber less risky.

\section{REFERENCES}

Angelelli E, R Mansini, MG Speranza. 2008. A comparison of MAD and CVaR models with real features. Journal of Banking \& Finance 32(7): 1188-1197.

Apiolaza LA, RM Alzamora. 2013. Building deployment portfolios for genotypes under performance instability. Silva Fennica 47(1): id 901.

Artzner P, F Delbaen, JM Eber, D Heath. 1999. Coherent measures of risk. Mathematical Finance 9(3): 203-228.

Konno H, H Yamazaki. 1991. Mean-Absolute Deviation Portfolio Optimization Model and Its Applications to Tokyo Stock Market. Management Science 37(5): 519-531.

Meneses MO, S Guzmán. 2003. Clasificación de rollizos y rodales. Informe $\mathrm{N}^{\circ} 5$ Proposición de un sistema de clasificación de trozas podadas y no podadas. Proyecto FONDEF D00I1159 “Maderas Clear”. Valdivia, Chile, Universidad Austral de Chile p. 164-178.

Park JC. 1989. Pruned log index. New Zealand Journal of Forest Science 19(1): 41-53.

Rockafellar R, S Uryasev. 2002. Conditional value-at-risk for general loss distributions. Journal of Banking and Finance 26: 1443-1471.

Topaloglou N, H Vladimirou, SA Zenios. 2002. CVaR models with selective hedging for international asset allocation. Journal of Banking \& Finance 26(7): 1535-1561.

Watt MS, JA Turner, EG. Mason. 2000. Genetic influence on second-log branching in Pinus radiata. New Zealand Journal of Forest Science 30 (3): 315-331.

WWPA (Western Wood Products Association, US). 1995. Western wood species book Vol.3: Factory lumber. Oregon, USA. Western Wood Products Association. 48 p.

Recibido: 03.03.14

Aceptado: 08.01.15 
